\title{
The Pattern of Respiratory Disease Morbidity and Mortality in a Tertiary Hospital in Southern-Eastern Nigeria
}

\author{
Victor Aniedi Umoh, ${ }^{1}$ Akaninyene Otu, ${ }^{2}$ Henry Okpa, ${ }^{3}$ and Emmanuel Effa ${ }^{3}$ \\ ${ }^{1}$ Department of Internal Medicine, University of Uyo, Uyo, Akwa Ibom State, Nigeria \\ ${ }^{2}$ University of Calabar, Nigeria \\ ${ }^{3}$ Department of Internal Medicine, University of Calabar, Nigeria
}

Correspondence should be addressed to Victor Aniedi Umoh; aaumoh@gmail.com

Received 31 July 2013; Revised 24 October 2013; Accepted 13 November 2013

Academic Editor: Hisako Matsumoto

Copyright (C) 2013 Victor Aniedi Umoh et al. This is an open access article distributed under the Creative Commons Attribution License, which permits unrestricted use, distribution, and reproduction in any medium, provided the original work is properly cited.

\begin{abstract}
Background. Respiratory complaints are commonly encountered in medicine and respiratory diseases place a high burden on healthcare infrastructure. Healthcare planning should be based on adequate information: this study will help us to analyze the pattern of respiratory disease admissions in the medical wards in a developing country. Methods. The medical records of patients admitted into the medical wards over a 5-year period were retrieved and reviewed. Information obtained included demography, diagnosis, comorbid conditions, and risk factors for respiratory disease. Results. Three thousand four hundred and ninety patients were admitted into the medical wards with 325 (9.3\%) of them diagnosed with a respiratory condition. There were 121 females and 204 males. The average age of the patients was $40.7 \pm 14.7$ years. Only $7 \%$ of the patients smoked cigarette. The commonest respiratory conditions were tuberculosis $(66.8 \%)$ and pneumonia (24.9\%). The commonest comorbidity was HIV infection (39.7\%). Tuberculosis/HIV coinfection rate was $50.7 \%$. HIV infection was the single most important predictor of an adverse outcome (OR 5.1, 95\% CI 2.05-12.7, P $<0.001)$. Conclusion. Infective conditions make up a large percentage of respiratory diseases in low income countries with HIV infection constituting a significant risk factor for a poor disease outcome.
\end{abstract}

\section{Introduction}

Respiratory complaints such as cough and catarrh are some of the commonest symptoms encountered in medicine. This is due in part to the large surface area; nearly $70 \mathrm{~m}^{2}$ of the lungs present to the atmosphere [1]. The atmosphere that we breathe is more than just "air." In reality, it is a complex mixture of ambient gases and environmental particulates to which pathogen containing droplets are added when respiratory secretions are coughed or sneezed out by others. Respiratory diseases constitute a major cause of morbidity and mortality worldwide. The top four respiratory diseases, lower respiratory tract infections, chronic obstructive pulmonary disease (COPD), tuberculosis, and lung cancer, are among the ten leading causes of death worldwide [2]. In Africa, lower respiratory tract infection and tuberculosis are ranked 2nd and 8th, respectively [3].
In developed countries, respiratory diseases feature prominently in the top ten causes of morbidity and mortality [4-7]. In Nigeria, lower respiratory tract infections constituted the second leading cause of death in all age brackets in 2002, a year in which TB was the seventh leading cause of death, accounting for $4 \%$ of all deaths [8]. In India another developing country, pneumonia and pulmonary tuberculosis ranked in the top five causes of death [9].

Health care demands are rapidly expanding and the trends are changing in developing countries. Upgrading of the health care system is a pressing need and the priorities are not always easy to define especially in a resource constrained system. The changes necessary to improve the health care systems should be evidence-based. There are few studies on the morbidity and mortality pattern of respiratory diseases in Africa and fewer still from Nigeria. This study was undertaken to address some of the issues concerning respiratory diseases in Nigeria. 


\section{Methods}

This was a retrospective study conducted in the University of Calabar Teaching Hospital (UCTH), Calabar Cross River state in the South-Eastern part of Nigeria. This Hospital is a 400-bed hospital with 40 beds spaces for medical admissions. The hospital serves as a training centre for undergraduate medical students and postgraduate Resident Doctors. It is also a referral centre for other secondary health facilities in this part of Nigeria.

The medical records of all patients admitted into the medical wards of UCTH over a five-year period from April 2008 to March 2013 were retrieved and reviewed and the following information was extracted: demographic data, diagnosis of respiratory disease, comorbidities, complications, duration of hospitalisation, cigarette smoking habit, and treatment outcome. Treatment outcome was defined as favourable if the patient was successfully treated and discharged or unfavourable if the patient died while on admission or discharges against medical advice (DAMA). Data was analysed using the computer program Statistical Package for the Social Sciences, version 16.0 (SPSS Inc., Chicago, IL, USA). Descriptive and frequency statistics were obtained for the variables studied. The chi-square test was used to evaluate associations between the categorical variables, and values of $P<0.05$ were considered statistically significant.

\section{Results}

3.1. General Characteristics of the Patients. Three thousand four hundred and ninety patients were admitted into the medical wards within the period of study. There were 2202 males and 1288 females with a male to female ratio of $1.7: 1$. Three hundred and twenty five patients were diagnosed with respiratory diseases constituting $9.3 \%$ of all the medical admissions. Two hundred and four were males $(9.3 \%$ of all male patients) and one hundred and twenty one were females (9.4\% of all female patients). The average age for the males was $41.4 \pm 14.3$ years with a range of $15-85$ years, while for the females it was $39.3 \pm 15.2$ years with a range of $19-85$ years. Sixty-four percent of the patients were less than 45 years old and $92 \%$ were less than 65 years old (Table 1). Most of the patients were farmers with $<5 \%$ being unemployed. Smoking was not common among the patients with only $7 \%$ smoking rate and only the males indulged in smoking.

3.2. Respiratory Diagnosis. Figure 1 shows the frequency of respiratory diseases among the patients. 217 (66.8\%) patients were diagnosed with pulmonary tuberculosis, 81 (24.9\%) with pneumonia, $16(4.9 \%)$ patients with asthma, 7 (2.2\%) patients with COPD, and only $2(0.6 \%)$ patients with lung cancer and interstitial lung disease. The distribution of the various conditions among the patients is shown in Table 2. There was no significant gender difference in frequency of chest disease. The age distribution of the chest diseases shows that tuberculosis and pneumonia were more common within the 30-44 years age bracket and least common within the 65+ age bracket. Asthma and COPD were more common within
TABLE 1: General characteristics of patients with respiratory diseases in UCTH.

\begin{tabular}{lccc}
\hline & Female & Male & Total \\
& $121(\%)$ & $204(\%)$ & $325(\%)$ \\
\hline Age & & & \\
$15-29$ & $41(33.8)$ & $42(20.6)$ & $83(25.5)$ \\
$30-44$ & $38(31.5)$ & $87(42.7)$ & $125(38.5)$ \\
$45-64$ & $33(27.3)$ & $58(28.4)$ & $91(28)$ \\
$65+$ & $9(7.4)$ & $17(8.3)$ & $26(8)$ \\
Occupation & & & \\
Farmer & $42(34.7)$ & $78(38.2)$ & $120(37.0)$ \\
Trader & $15(12.4)$ & $35(17.1)$ & $50(15.4)$ \\
Public servant & $31(25.6)$ & $52(25.5)$ & $83(25.5)$ \\
Semiskilled & $23(19.0)$ & $34(17.7)$ & $57(17.5)$ \\
Unemployed & $10(8.3)$ & $5(2.5)$ & $15(4.6)$ \\
Smoker & $0(0.0)$ & $23(11.3)$ & $23(7.1)$ \\
\hline
\end{tabular}

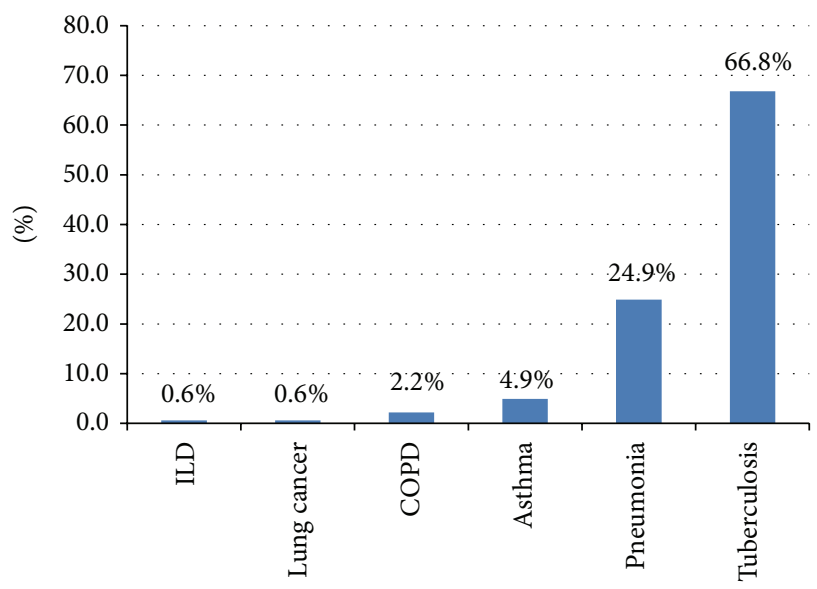

FIGURE 1: Frequency of respiratory conditions among patients in the medical wards.

the 45-64 years age bracket followed by the 15-29 and 3044 years age bracket. There was also one case of interstitial lung disease (ILD) in the age brackets of 30-44 and 65+. There was one case of lung cancer among patients aged 3444 years and 45-64 years. The differences were statistically significant $(P=0.001)$. Smoking was significantly associated with COPD, lung cancer, and chest infections $(P=0.007)$. HIV infection was significantly associated with tuberculosis and pneumonia $(P<0.0001)$.

3.3. Comorbid Conditions. Figure 2 shows the distribution of comorbidities among the patients with chest diseases. One hundred and fifty six (48\%) of the patients had one comorbidity or the other. The commonest comorbidity was HIV infection (39.7\%). Eleven (3.4\%) of the patients had diabetes mellitus. Eight (2.5\%) of the patients had congestive cardiac failure. There were three patients each with stroke, chronic liver disease, and septicaemia, while two patients had other malignancies other than lung cancer. 
TABLE 2: Distribution of respiratory conditions among patients.

\begin{tabular}{|c|c|c|c|c|c|c|c|}
\hline & $\begin{array}{c}\text { Tuberculosis } \\
N=217(\%)\end{array}$ & $\begin{array}{l}\text { Pneumonia } \\
N=81(\%)\end{array}$ & $\begin{array}{c}\text { Asthma } \\
N=16(\%)\end{array}$ & $\begin{array}{c}\text { COPD } \\
N=7(\%)\end{array}$ & $\begin{array}{l}\text { Lung ca. } \\
N=2(\%)\end{array}$ & $\begin{array}{c}\text { ILD } \\
N=2(\%)\end{array}$ & $P$ \\
\hline \multicolumn{8}{|l|}{ Gender } \\
\hline Female & $80(36.9)$ & $28(34.6)$ & $9(56.2)$ & $3(42.9)$ & $0(0.0)$ & $1(50.0)$ & \multirow{2}{*}{0.53} \\
\hline Male & $137(63.1)$ & $53(65.4)$ & $7(43.8)$ & $4(57.1)$ & $2(100)$ & $1(50.0)$ & \\
\hline \multicolumn{8}{|l|}{ Age } \\
\hline $15-29$ & $60(27.6)$ & $18(22.2)$ & $4(25)$ & $1(14.3)$ & $0(0.0)$ & $0(0.0)$ & \multirow{4}{*}{0.001} \\
\hline $30-44$ & $90(41.5)$ & $29(35.8)$ & $4(25)$ & $0(0.0)$ & $1(50.0)$ & $1(50)$ & \\
\hline $45-64$ & $58(26.7)$ & $20(24.7)$ & $7(43.8)$ & $5(71.4)$ & $1(50.0)$ & $0(0.0)$ & \\
\hline $65+$ & $9(4.2)$ & $14(17.3)$ & $1(6.2)$ & $1(14.3)$ & $0(0.0)$ & $1(50)$ & \\
\hline HIV+ve & $110(50.7)$ & $18(22.2)$ & $1(6.2)$ & $0(0.0)$ & $0(0.0)$ & $0(0.0)$ & $<0.001$ \\
\hline Smoking & $17(7.8)$ & $5(6.2)$ & $0(0.0)$ & $2(28.6)$ & $2(100)$ & $0(0.0)$ & 0.007 \\
\hline
\end{tabular}

Lung ca.: lung cancer

ILD: interstitial lung disease.

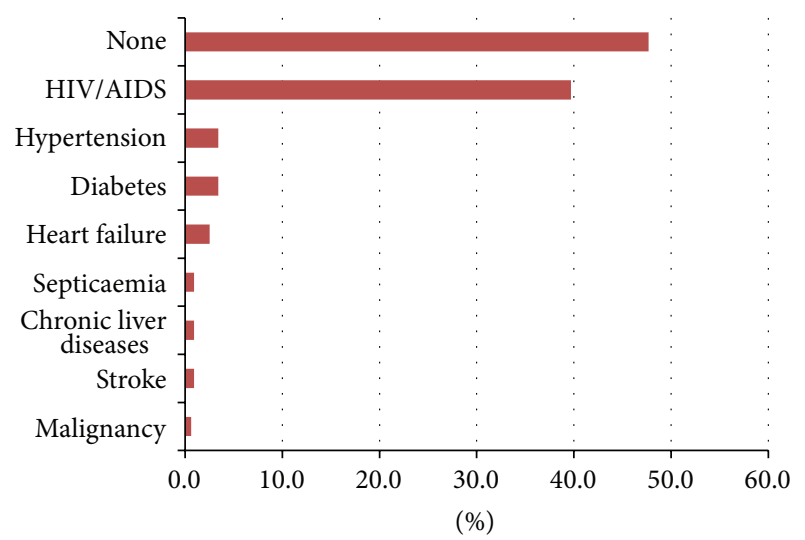

FIGURE 2: Frequency of comorbidities among respiratory diseases patients.

3.4. Duration of Hospitalisation. The average duration of hospitalisation was $15.4 \pm 6.4$ days with a range between 3 and 35 days. Patients with interstitial lung disease spent the most days in hospital $(21 \pm 9.9)$ followed by patients with tuberculosis and lung cancer, $17.6 \pm 5.2$ days and $17 \pm 11.3$ days, respectively. Asthma patients spent the least number of days in hospital; $8.3 \pm 2.5$ days (Table 3 ). A one way analysis of variance test was conducted to explore the impact of the respiratory diagnosis on the duration of hospital stay. Patients were divided into six groups based on their diagnosis. There was a statistically significant difference in duration of hospital admission for the six groups $F(5,319)=$ 38.9, $P<0.0001$. The diagnosis had a large effect on the duration of hospitalisation (Eta squared 0.37). Post hoc analysis using Tukey-HSD indicated that the duration of stay for tuberculosis was significantly longer than that of asthma and pneumonia.

3.5. Treatment Outcome. Two hundred and ninety (89.2\%) patients were treated successfully and discharged form hospital and $30(9.2 \%)$ died while on admission, while five $(1.6 \%)$
TABLE 3: Average duration of hospital stay based on the respiratory condition.

\begin{tabular}{lccc}
\hline \multirow{2}{*}{ Diagnosis } & Mean (SD) & \multicolumn{2}{c}{$95 \%$ CI } \\
& & Lower & Upper \\
\hline Asthma & $8.25(2.5)$ & 6.91 & 9.59 \\
Pneumonia & $9.14(5.0)$ & 8.03 & 10.25 \\
Tuberculosis & $17.63(5.2)$ & 16.94 & 18.33 \\
Lung cancer & $17.0(11.3)$ & -84.65 & 118.65 \\
COPD & $16.14(5.7)$ & 10.85 & 21.44 \\
ILD & $21.0(9.89)$ & -67.94 & 109.94 \\
\hline
\end{tabular}

ILD: interstitial lung disease.

patients DAMA; Figure 3. All $35(10.8 \%)$ patients had an unfavourable outcome. There was no significant association between the diagnosis and the final outcome (Table 4).

Direct logistic regression analysis was performed to assess the impact of certain factors on an unfavourable outcome. The model contained seven variables: age, duration of hospital stay, gender, cigarette smoking, HIV infection, tuberculosis, and lung cancer. The full model was statistically significant $\chi^{2}=29.066$ and $P<0.001$, indicating that the model could distinguish patients who had a favourable outcome from those with an unfavourable outcome. The model could explain up to $17.3 \%$ of the variance in outcome (Negelkerke $R$ squared) and correctly classified $90 \%$ of the patients. Only HIV infection made a unique significant contribution to the model (OR 5.1, $P<0.0001$ ) indicating that patients with HIV infection were over five times more likely to have an unfavourable outcome (Table 5).

\section{Discussion}

Respiratory diseases constituted $9.3 \%$ of medical admissions in this survey. Similar observations have been reported by other investigators. Desalu et al. [10] in Ilorin, North-Central Nigeria, reported that respiratory diseases make up $8.7 \%$ of all medical admissions. Respiratory diseases accounted for 
TABLE 4: Diseases outcome according to respiratory condition.

\begin{tabular}{lcccccc}
\hline & Asthma & Pneumonia & Tuberculosis & Lung ca. & COPD & ILD \\
& $16(\%)$ & $81(\%)$ & $217(\%)$ & $2(\%)$ & $7(\%)$ & $2(\%)$ \\
\hline Discharged & $16(100)$ & $74(91.4)$ & $192(88.5)$ & $0(0.0)$ & $6(85.7)$ & $2(100)$ \\
DAMA & $0(0.0)$ & $1(1.2)$ & $4(1.8)$ & $0(0.0)$ & $0(0.0)$ & $0(0.0)$ \\
Died & $0(0.0)$ & $6(7.4)$ & $21(9.7)$ & $2(100)$ & $1(14.3)$ & $0(0.0)$ \\
\hline
\end{tabular}

Lung ca.: lung cancer

ILD: interstitial lung disease.

TABLE 5: Predictors of unfavourable outcome among patients with respiratory conditions.

\begin{tabular}{lcccc}
\hline Parameter & OR & $P$ & Lower & U5\% CI for OR \\
\hline Age & & & 0.97 & 1.03 \\
Hospital stay & 0.99 & 0.96 & 0.91 & 1.05 \\
Gender & 0.98 & 0.58 & 0.22 & 1.13 \\
Smoking & 0.5 & 0.09 & 0.65 & 11.5 \\
HIV infection & 2.74 & 0.17 & 2.05 & 12.7 \\
TB infection & 5.1 & 0.001 & 0.36 & 2.97 \\
Lung cancer & 1.03 & 0.99 & 0.00 & \\
\hline
\end{tabular}

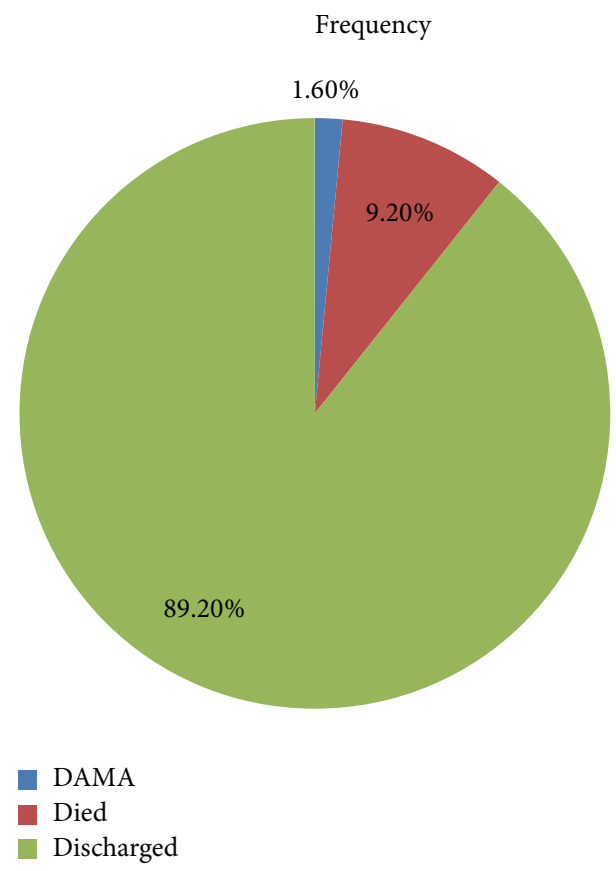

FIGURE 3: Outcome among patients with respiratory disease.

a higher percentage $(14.5 \%)$ of medical admissions in Saudi Arabia [11] and 31.73\% in Kathmandu, Nepal [12]. The much higher prevalence of respiratory diseases in the Saudi survey and Kathmandu may be due to the higher prevalence of a major risk factor for respiratory diseases in these desert areas with many pilgrims: cigarette smoking which may be as high as $53 \%$ in some of these areas $[13,14]$ among other factors. This stands in contrast to the observed smoking rate in this study (7\%) as well as in a previous Nigerian report of $8.7 \%$ [15].

Tuberculosis was the commonest respiratory condition followed by pneumonia. Together they account for over $90 \%$ of respiratory admissions. In Ilorin Central Nigeria, chest infections were the most important causes of respiratory disease hospitalisation with tuberculosis and pneumonia occupying the first and third most frequent indications for hospitalisation [10]. This contrasts sharply with observations from other parts of the world where chronic noninfective respiratory diseases predominate $[11,12]$.

Young patients $<45$ years made up $>60 \%$ of the admissions in this study. This picture is similar to what was observed in a previous study from Nigeria by Desalu et al. [10] in that study most of the patients were young adults $<45$ years. This can be explained by the demographic pattern of Nigeria where $>80 \%$ of the population is $<45$ years [16]. This pattern contrasts with observations in the ward admissions of patients with respiratory diseases in other parts of the world where older patients make up the bulk of the respiratory diseases admissions $[4-6,11]$.

The most common comorbidity in this study was HIV infection with a prevalence of $39.7 \%$ and a tuberculosis coinfection rate of $50.7 \%$. HIV has been shown to have a strong association with tuberculosis. Pennap et al. [17] in Keffi, North-Central Nigeria reported a prevalence of $44.2 \%$ for tuberculosis/HIV coinfection. Studies from regions with a low prevalence of HIV have reported a different pattern for the comorbidities; diabetes and hypertension being the most common comorbidities [11].

The average duration of hospitalisation was $15.4 \pm 6.4$ days. A previous local study reported the duration of hospitalisation for medical admissions of $15.6 \pm 13.8$ days [18]; this shows that on average respiratory disease patients did not spend more time on admission than medical conditions 
of other systems. Hospital stay in this study was significantly longer for ILD and tuberculosis patients compared with pneumonia and asthma $(P<0.05)$. This is similar to observations by Desalu et al. [10] where they reported the average duration of hospitalisation for respiratory diseases to be 14 days with pneumonia and asthma accounting for the shortest duration of hospitalisation. Alamoudi [11] in Saudi Arabia reported similar findings; a majority of asthma and pneumonia patients were hospitalised for less than a week, while ILD, tuberculosis, and bronchiectasis accounted for most of the patients that spent more than two weeks on admission.

Thirty $(9.2 \%)$ patients died while five patients DAMA. Lung cancer recorded $100 \%$ mortality in this study. Mortality from lung cancer is high all over the world [19]. Smoking is a major risk factor for lung cancer [20]. In this study, all the patients with lung cancer had a significant smoking history. The smoking rate is on the increase in low income countries [3] as such we should expect an increase in the incidence and mortality from lung cancer in the coming years. In this study one death was attributed to COPD. With the increasing rate of smoking in low income countries we should also expect an increase in morbidity and mortality from this condition.

$11.5 \%$ of patients with tuberculosis had an unfavourable outcome. Different investigators have reported varying mortality rates for tuberculosis. Our observations on mortality is similar to a report of mortality rate of $10.1 \%$ among 4000 tuberculosis patients in Ethiopia by Tessema et al. [21] and Busari et al. [22] in Ido-Ekiti South-West, Nigeria. A much higher mortality rate was observed by Salako and Sholeye in Sagamu, South-West, Nigeria. In their study $23.2 \%$ of the hospitalised patient had unfavourable outcome [23]. The different mortality rates may be a reflection of the difference in diseases severity in those centres.

HIV infection was the only condition with a unique significant contribution to an adverse outcome in this study after controlling for confounders (OR 5.1, 95\% CI 2.05-12.7, and $P<0.001)$. The probability of dying or abandoning treatment among patients with respiratory disease was five times higher for patients with concomitant HIV infection than for patients without HIV infection. Several studies from Nigeria have described the critical role of HIV infection as a cause of morbidity and mortality in hospitalised patients $[24,25]$. Studies have also revealed that HIV/AIDS patients in Nigeria tend to present late with advanced illnesses [26]. Thus compounding the outcome in this very serious disease condition.

There are several limitations of this study. First of all this was a retrospective study as such we encountered some poor and incomplete record keeping which affected our ability to quantify some variables. It is worthy to note that certain diseases, such as bronchiectasis, pulmonary vascular diseases, sleep apnoea, pneumocystis jirovecii pneumonia (PCP), sarcoidosis, collagen lung diseases, overlap syndromes of asthma and COPD, and pneumoconiosis were not reported. This may be due to a lack of awareness and a low index of suspicion from the attending physicians. In conclusion this study has highlighted the high burden of respiratory diseases in our hospital and the role of tuberculosis and HIV coinfections as a major cause of morbidity and mortality.

\section{Disclosure}

Dr. Victor Aniedi Umoh will act as the guarantor. This study in part or as a whole has not been published or presented in any journal or conference before. No other person or body has been given permission to reproduce any information or material in this paper.

\section{Conflict of Interests}

The authors have no conflict of interests whatsoever.

\section{References}

[1] M. Ochs and E. R. Weibel, "Functional design of the human lungs for gas exchange," in Fishman's Pulmonary diseases and disorders, vol. 10036, pp. 23-25, McGraw Hill, New York, NY, USA, 4th edition, 2008.

[2] R. Lozano, M. Naghavi, K. Foreman et al., "Global and regional mortality from 235 causes of death for 20 age groups in 1990 and 2010: a systematic analysis for the Global Burden of Disease Study 2010," The Lancet, vol. 380, pp. 2095-2128, 2012.

[3] WHO, "Global Burden of Disease: 2004 update," vol. 1211, World Health Organisation, Geneva, Switzerland, 2008 http://www.who.int/healthinfo/global_burden_disease/2004_ report_update/en/index.html.

[4] BTS, "The burden of lung disease: a statistical report from the British Thoracic Society," 2nd ed., British Thoracic Society, London, UK, 2006, http://www.brit-thoracic.org.uk/deliveryof-respiratory-care/burden-of-lung-disease-reports.aspx.

[5] R. Hubbard, "The burden of lung disease," Thorax, vol. 61, no. 7, pp. 557-558, 2006.

[6] R. Loddenkemper, G. J. Gibson, and Y. Sibille, "Respiratory health and disease in Europe: the new European Lung White Book," European Respiratory Journal, vol. 42, pp. 559-563, 2013.

[7] D. E. Schraufnagel, F. Blasi, M. Kraft, M. Gaga, P. Finn, and K. F. Rabe, "An official American Thoracic Society and European Respiratory Society policy statement: disparities in respiratory health," European Respiratory Journal, vol. 42, pp. 906-915, 2013.

[8] WHO, "Country Health System Fact Sheet 2006: Nigeria," WHO, Geneva, Switzerland, 2006, http://www.afro.who.int/ home/countries/fact_sheets/nigeria.pdf.

[9] A. Ramanakumar and C. Aparajita, "Respiratory disease burden in rural India: a review from multiple data sources," The Internet Journal of Epidemiology, vol. 2, no. 2, 2005.

[10] O. O. Desalu, J. A. Oluwafemi, and O. Ojo, "Respiratory diseases morbidity and mortality among adults attending a tertiary hospital in Nigeria," Jornal Brasileiro de Pneumologia, vol. 35, no. 8, pp. 745-752, 2009.

[11] O. S. Alamoudi, "Prevalence of respiratory diseases in hospitalized patients in Saudi Arabia: a 5 years study 1996-2000," Annals of Thoracic Medicine, vol. 1, no. 2, pp. 76-80, 2006.

[12] B. R. Pokharel, S. Humagain Pant P, R. Gurung, R. Koju, and T. R. Bedi, "Spectrum of diseases in a medical ward of a teaching hospital in a developing country," Journal of College of Medical Sciences-Nepal, vol. 8, no. 2, pp. 7-11, 2012. 
[13] A. El-Menyar, M. Zubaid, A. Shehab et al., "Prevalence and impact of cardiovascular risk factors among patients presenting with acute coronary syndrome in the middle east," Clinical Cardiology, vol. 34, no. 1, pp. 51-58, 2011.

[14] C. T. Sreeramareddy, N. Ramakrishnareddy, H. N. Harsha Kumar, B. Sathian, and J. T. Arokiasamy, "Prevalence, distribution and correlates of tobacco smoking and chewing in Nepal: a secondary data analysis of Nepal Demographic and Health Survey-2006," Substance Abuse, vol. 6, no. 1, article 33, 2011.

[15] E. G. Adepoju, S. A. Olowookere, N. A. Adeleke, O. T. Afolabi, F. O. Olajide, and O. O. Aluko, "A population based study on the prevalence of cigarette smoking and smokers' characteristics at Osogbo, Nigeria," Tobacco Use Insights, vol. 6, pp. 1-5, 2013.

[16] National Population Commission (NPC) [Nigeria] and ICF Macro, "Nigeria Demographic and Health Survey 2008," National Populaton Commission and ICF Macro, Abuja, Nigeria, 2009, http://www.measuredhs.com/pubs/pdf/FR222/ FR222.pdf.

[17] G. Pennap, S. Makpa, and S. Ogbu, "The prevalence of HIV/AIDS among tuberculosis patients in a tuberculosis/ leprosy Referral Center in Alushi, Nasarawa State, Nigeria," The Internet Journal of Epidemiology, vol. 8, no. 1, 2010.

[18] E. O. Sanya, T. M. Akande, G. Opadijo, J. K. Olarinoye, and B. J. Bojuwoye, "Pattern and outcome of medical admission of elderly patients seen at University of Ilorin Teaching Hospital, Ilorin," African Journal of Medicine and Medical Sciences, vol. 37, no. 4, pp. 375-381, 2008.

[19] P. Paliogiannis, F. Attene, A. Cossu et al., "Lung cancer epidemiology in North Sardinia, Italy," Multidisciplinary Respiratory Medicine, vol. 8, no. 1, article 45, 2013.

[20] V. N. Davis, A. Lavender, R. Bayakly, K. Ray, and T. Moon, "Using current smoking prevalence to project lung cancer morbidity and mortality in Georgia by 2020," Preventing Chronic Disease, vol. 10, Article ID 120271, 2013.

[21] B. Tessema, A. Muche, A. Bekele, D. Reissig, F. Emmrich, and U. Sack, "Treatment outcome of tuberculosis patients at Gondar University Teaching Hospital, Northwest Ethiopia. A five - Year retrospective study," BMC Public Health, vol. 9, article 371, 2009.

[22] O. A. Busari, O. T. Olarewaju, and O. E. Busari, "Management and outcomes of suspected pulmonary tuberculosis in a resource-poor setting," Internet Journal of Pulmonary Medicine, vol. 11, no. 2, 2010.

[23] A. A. Salako and O. O. Sholeye, "Management outcomes of tuberculosis cases in a tertiary hospital in Southwestern Nigeria," Journal of Community Medicine and Health Education, vol. 2, no. 2, article 122, 2012.

[24] D. Ogoina, R. O. Obiako, H. M. Muktar, M. Adeiza, A. Babadoko, and A. Hassan, "Morbidity and mortality patterns of hospitalised adult HIV/AIDS patients in the era of highly active antiretroviral therapy: a 4-year retrospective review from Zaria, Northern Nigeria," AIDS Research and Treatment, vol. 2012, Article ID 940580, 10 pages, 2012.

[25] A. N. Gyuse, I. E. Bassey, N. E. Udonwa, I. B. Okokon, and E. E. Philip-Ephraim, "HIV/AIDS related mortality among adult medical patients in a tertiary health institution in South-South, Nigeria," Asian Pacific Journal of Tropical Medicine, vol. 3, no. 2, pp. 141-144, 2010.

[26] C. Akolo, C. O. Ukoli, G. N. Ladep, and J. A. Idoko, "The clinical features of HIV/AIDS at presentation at the Jos University Teaching Hospital," Nigerian Journal of Medicine, vol. 17, no. 1, pp. 83-87, 2008. 


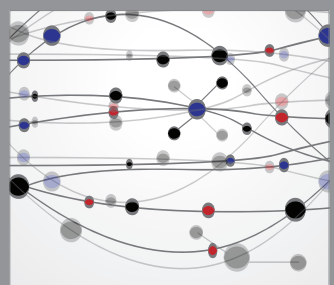

The Scientific World Journal
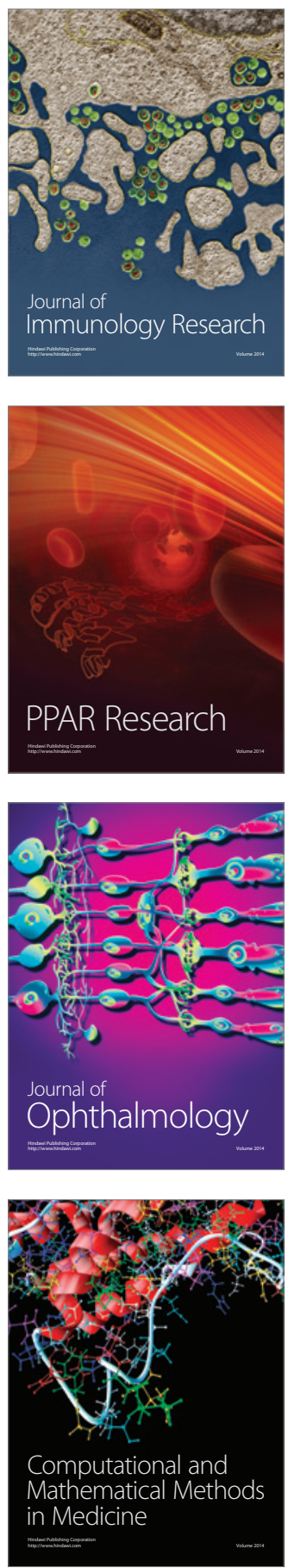

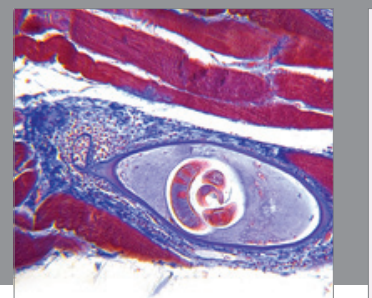

Gastroenterology

Research and Practice
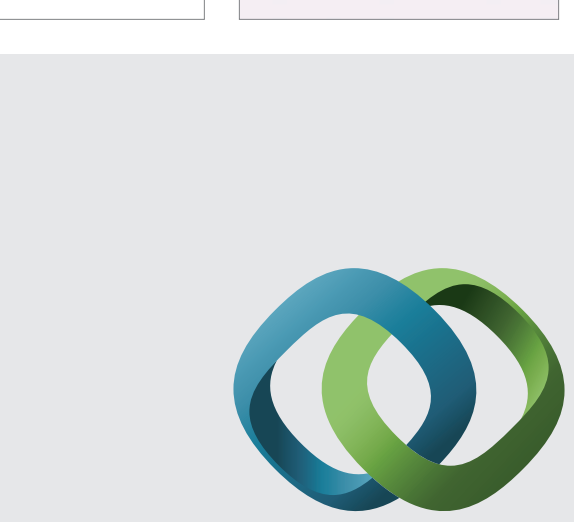

\section{Hindawi}

Submit your manuscripts at

http://www.hindawi.com
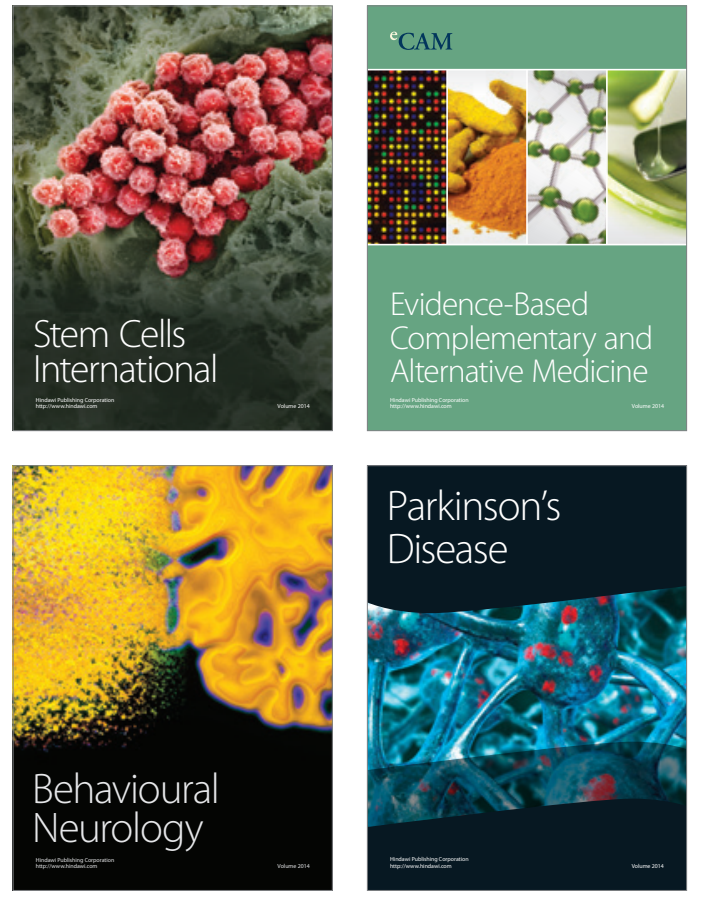
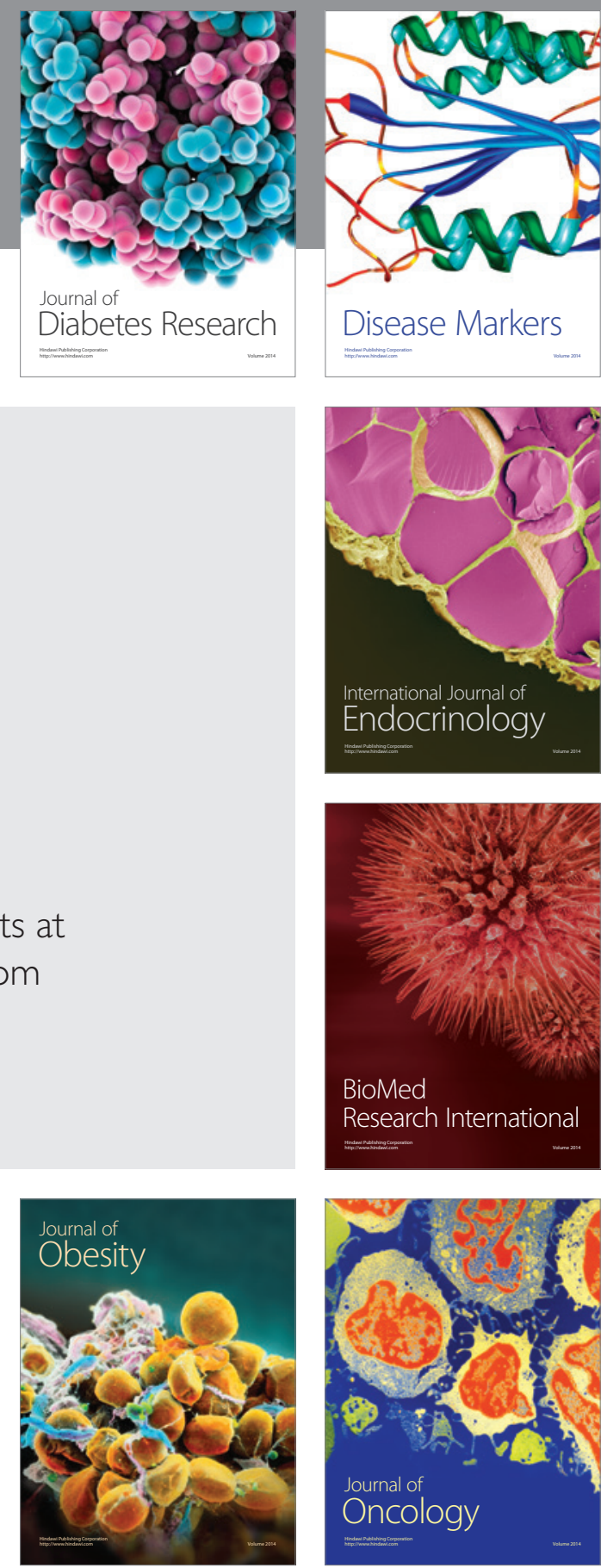

Disease Markers
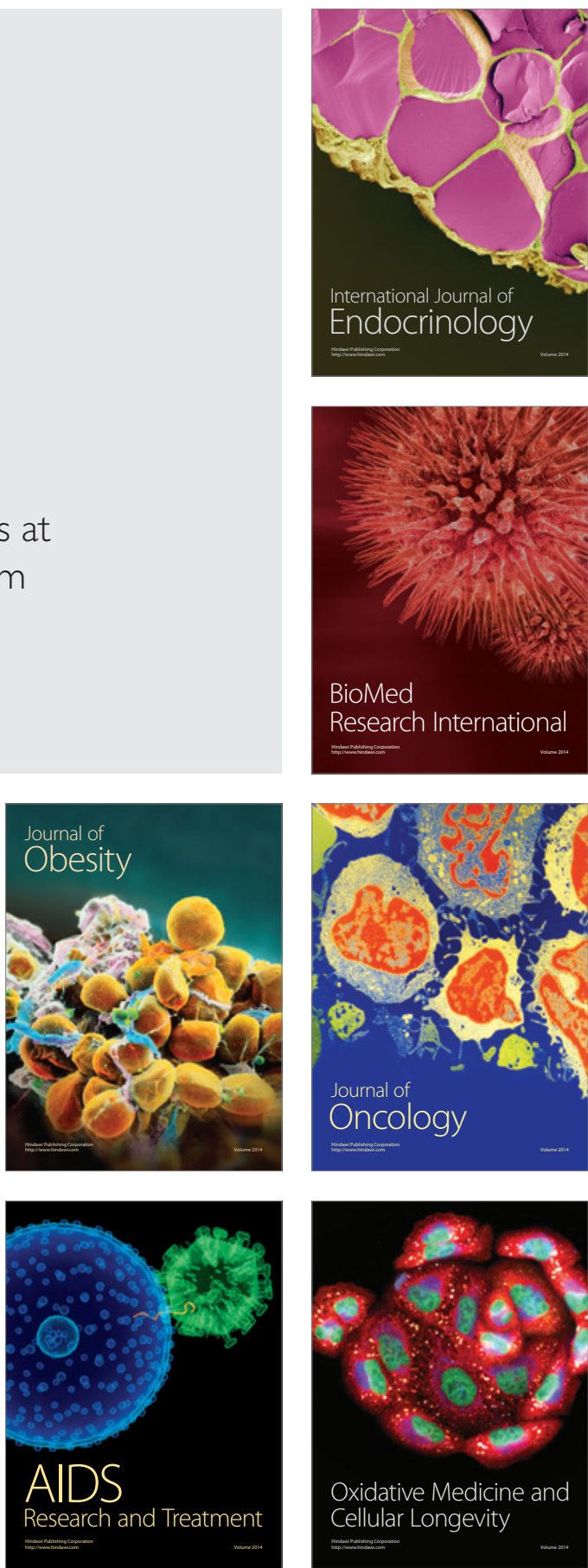